\title{
Sustainable production of polyhydroxyalkanoates from renewable oil-palm biomass
}

\begin{abstract}
With rapid industrialization and increasing per-capita consumption of conventional plastics, there is a growing need for the development of bio-based materials from renewable resources to reduce the environmental footprint of plastic production. Oil palm biomass, which is the largest biomass in Malaysia, has tremendous potential as a primary or secondary feedstock for polyhydroxyalkanoate (PHA) production. PHA production can be made more competitive and sustainable by using oil palm biomass effluent and residues that are available at the factories. The oil palm biomass as non-food biomass from the mill is a great strategy towards zero discharge in palm oil industry by combining wastewater treatment system for mixed organic acids production together with PHA production from the clarified organic acids. Hence, several oil palm biomass have been explored and considered as sustainable promising sources for PHA production in future. Solid waste such as oil palm frond and oil palm empty fruit bunch can be used as sugar based substrate. In addition, palm oil mill effluent can be effectively converted to mixed organic acids and glycerol as wastes from palm oil based biodiesel processing plant are suitable for PHA production. The successful bioconversion and utilization of oil palm biomass can reduce the production costs of PHAs and minimize greenhouse-gas emissions. This article provides an overview of various types of biomass generated by the palm oil industry and describes their bioconversion into PHAs by various PHA producers. Future perspectives and challenges for the commercialization of PHAs produced using oil palm biomass are also discussed.
\end{abstract}

Keyword: Oil-palm biomass; Bioplastics; Polyhydroxyalkanoates; Sustainability; Malaysia 